Bull. Mater. Sci., Vol. 13, No. 3. June 1990, pp. 227-234. (C) Printed in India.

\title{
Standardization of investment casting process using modified binder hydrolysis
}

\author{
KAYALA MALLIKHARJUNA BABU ${ }^{1}$, P MARTIN JEBARAJ $^{2}$ and \\ M P CHOWDIAH ${ }^{3}$ \\ ${ }^{1}$ Department of Mechanical and Industrial Production Engineering, Dr Ambedkar \\ Institute of Technology, Bangalore 560056 , India \\ ${ }^{2}$ Department of Mechanical Engineering, M S Ramaiah Institute of Technology, \\ Bangalore 560 054, India \\ ${ }^{3}$ Department of Mechanical Engineering, University Vishveshwarayya College of \\ Engineering, Bangalore 560001 , India
}

MS received 15 June 1989

\begin{abstract}
A full factorial $2^{3}$ matrix was designed to study the bending strength, permeability and hoop-stress of investment moulds. A novel method of ethyl-silicate hydrolysis; two-step hydrolysis, was used. The results indicate that the bending strength is directly proportional to the quantity of filler material in the slurry. Grain size of stucco material appears to exert the least effect on bending and hoop strength, whereas permeability increases slightly when coarser grain is used.
\end{abstract}

Keywords. Investment casting; filler material; binder; gel time; stucco material; ethyl silicate; hydrolysis; factorial experiment.

\section{Introduction}

The investment casting process (Shah 1975; Babu 1988) consists of applying investment in layers by alternatively dipping the pattern into a slurry containing bonding agent and then sprinkling with refractory stucco material. These operations are repeated until the required thickness of shell is built up. The process consists of the following stages; preparation of the pattern, application of dip coat to the pattern, application of the stucco, drying and hardening of the coating, removal of wax from the shell, firing and casting.

The failure of the process may be attributed to the inadequate level of siloxane bond radicals obtained by using ethyl silicate (Kenny and Rutt 1959; Busyman and Van Embden 1963; Shepherd and Lewis 1989). To help in improving binder content and thus eliminate the failure rate, a relatively basic laboratory investigation was undertaken to identify, quantify and inter-relate the governing physico-chemical processes (Tagger 1963) involved in the hydrolysis reaction of ethyl silicate and to arrive at an optimum composition of ethyl silicate base binder solution and slurry using indigenous materials which in turn, gives the desirable and sufficient strength to the ceramic shells with an adequate shell or working life to the binder slurry (Tkancheno and Rovnova 1963; Doskar and Gabriel 1967).

\section{Aim}

Investment shells made using general single step hydrolysis, has shown lesser strength (Doelman 1966). This is due to the low level of binder content (i.e. $\mathrm{SiO}_{2}$ amount of 8 to $10 \%$ ). In the present investigation an attempt is made to increase the 
concentration of binder content to a level of about $20 \%$ using a modified hydrolysis principle, referred to here as 'two-step hydrolysis', adapted for this purpose. Further, in order to produce very sound casting one should have a knowledge of various factors affecting the physico-chemical process occurring (Doelmann 1966) in the investment. Such factors are ethyl silicate content, filler material and filler to binder ratio. Some of these are also considered in the study.

\section{Experimental procedure}

The effect of the quantity of filler material, gelling time and size of stucco sand on bending strength, permeability and hoop strength were tested. Strip samples for bending tests were made using perspex sheets of dimensions $25 \times 100 \mathrm{~mm}^{2}$. A $4 \mathrm{~mm}$ thick layer was built on either side of the perspex sheet by dipping and stuccoing six times in the slurry. The strips were removed by surface grinding and cut into $25 \times 30 \mathrm{~mm}^{2}$ size. These specimens were tested using a universal sand strength testing machine having modified shackles. The shackles are modified to suit $25 \times 30 \mathrm{~mm}^{2}$ size samples (Shah 1975). Bending strength values were calculated from the load value indicated in the sand testing machine. A permeability test sample was made from a standard tennis ball as pattern to which a hollow brass tube of $150 \mathrm{~mm}$ length was fixed using an adhesive (figure 1). The investment shell was built upon the ball surface from slurry by dipping and stuccoing. After making six layers, the shell with pattern was heated to above $600^{\circ} \mathrm{C}$ and the plastic ball was burnt out. The brass tube end of the sample was connected to the standard

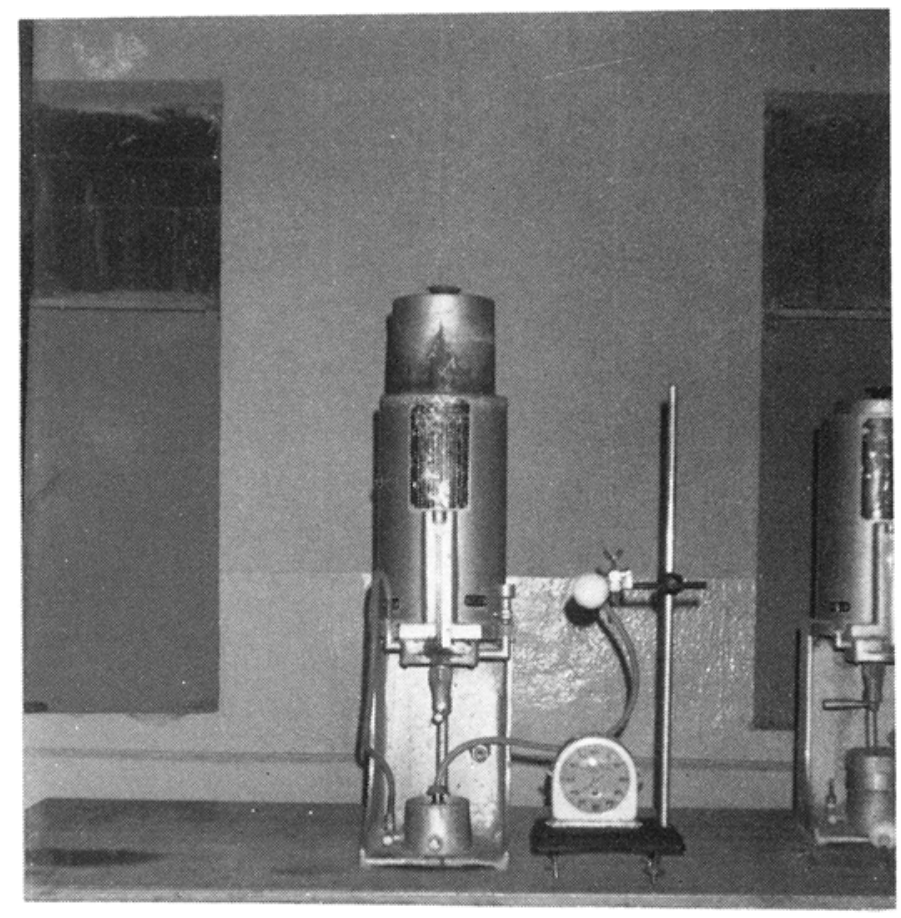

Figure 1. Experimental set up for permeability testing. 
permeability tester. The time taken to pass $1000 \mathrm{ml}$ air was taken as the permeability index. Hoop stress was determined by the same type of investment mould adopted for measuring permeability. Compressed air was passed through a $T$ junction valve. One end of the pipe junction was fixed to the sample's copper rod holder and another end to a pressure transducer. This set up is shown in figure 2. Compressed air was forced into the spherical shell specimen and the pressure at which it broke was recorded as the bursting strength of the shell. Lame's theorem (Babu 1988) was used to get the internal and external hoop stress acting on the sample.

\section{Results and discussion}

Experimental design and regression analysis are effected assuming the following hypotheses (tables 1 and 2): (a) the optimization parameter $Y$ (here bending strength, permeability and hoop stress) is a random population normally distributed. (b) the variance of $Y$ does not depend upon its absolute value. (c) A linear mathematical model is suitable for the factors considered.

\section{$4 \cdot 1$ Variance of reproducibility}

Using the definition (Cochran and Cox 1959).

$$
S^{2}(Y)=\sum_{1}^{N}-\left[n\left(Y_{i g}-Y_{i}\right)^{2} / N(n-1)\right] .
$$

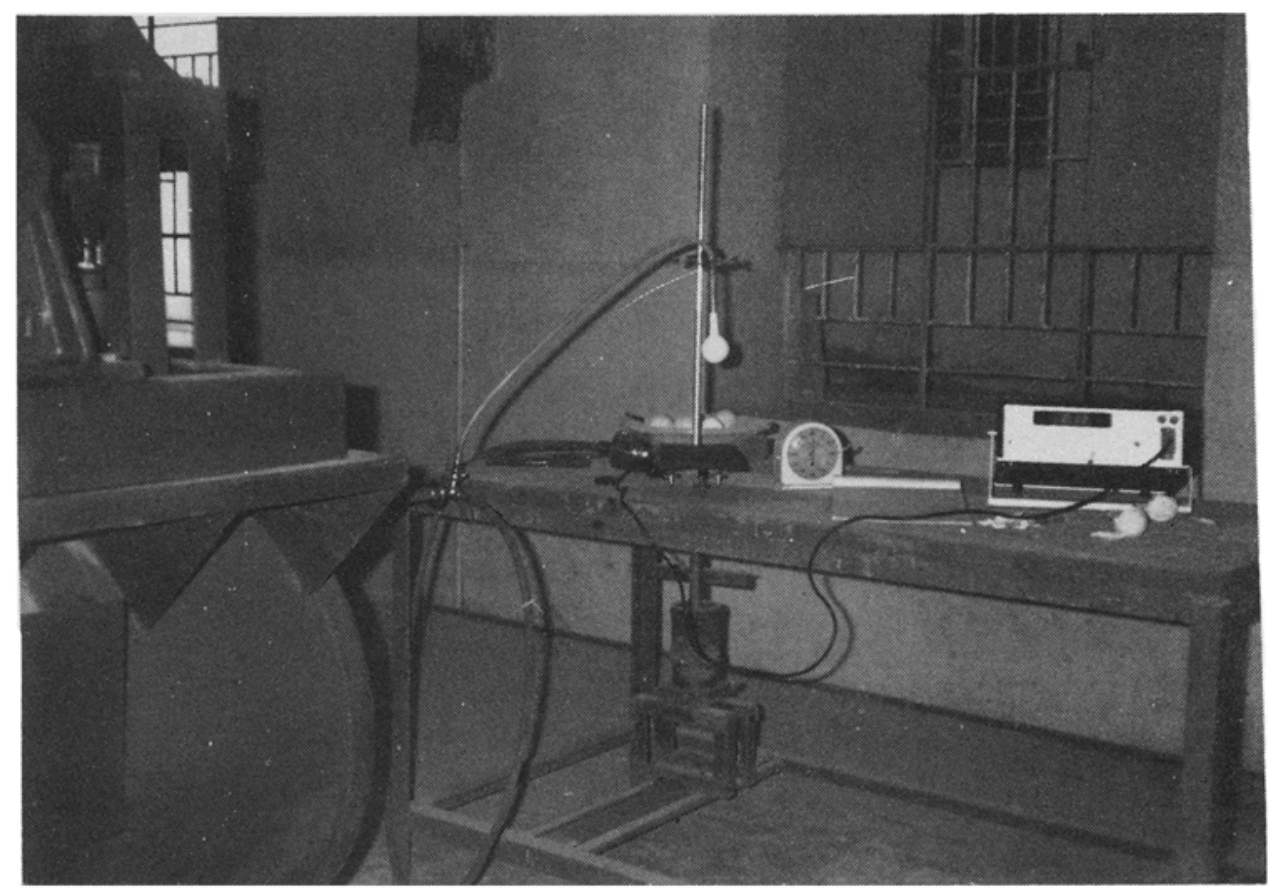

Figure 2. Set up for testing bursting strength. 
Table 1. Upper and Lower levels of variables.

\begin{tabular}{lccc}
\hline Level & $\begin{array}{c}\text { Filler material } \\
(\mathrm{g})\end{array}$ & $\begin{array}{c}\text { Gel time } \\
(\mathrm{s})\end{array}$ & $\begin{array}{c}\text { Stucco size } \\
\text { (AFS No.) }\end{array}$ \\
\hline Upper $(+)$ & 340 & 25 & 50 \\
Lower $(-)$ & 260 & 5 & 70 \\
\hline
\end{tabular}

The variance of reproducibility was calculated for each parameter. The values are found to be $30.50,0.0108,1.939$ and 0.9435 , respectively, for bending strength, permeability, internal hoop stress and external hoop stress.

\subsection{Homogeneity of variance}

Using Cochran's criterion (Cochran and Cox 1959), which is the ratio of the maximum variance of one of the eight treatments to the sum of all the variances for every treatment, viz

$$
G=S_{\max }^{2} / \sum_{1}^{n} S_{t}^{2}
$$

where $S_{t}^{2}=\sum_{1}^{N}\left(Y_{i g}-Y_{i}\right)^{2} /(n-1)$

The experimental values of Cochran's ratios for the bending strength, permeability, internal hoop stress and external hoop stress, are 0.391, 0.390, 0.376, and $0 \cdot 350$ respectively. All these values are less than $0 \cdot 690$, the tabulated values for a $2^{3}$ matrix with two replications of each treatment. Thus, the homogeneity of variance for each parameter noted above is confirmed and the prerequisite for the application of regression analysis of these experimental results is satisfied.

\subsection{Regression analysis}

It is assumed that the relation between the optimization parameter and the variables can be expressed in the form

$$
Y=a_{0}+a_{1} x_{1}+a_{2} x_{2}+a_{3} x_{3} \text {. }
$$

Using the least squares method for an orthogonal matrix, as employed in this investigation, the regression coefficient may be evaluated as

$$
\begin{aligned}
a_{0}= & \sum_{1}^{N} Y_{i} / N, \\
a_{1}= & \sum_{1}^{N} Y_{i} x_{1 i} / N, \\
a_{2}= & \sum_{1}^{N} Y_{i} x_{2 i} / N, \\
a_{3}= & \sum_{1}^{N} Y_{i} x_{3 i} / N,
\end{aligned}
$$

where $Y_{i}$ is the response in the $i$ th treatment. For the present experimental results the regression equations are: 


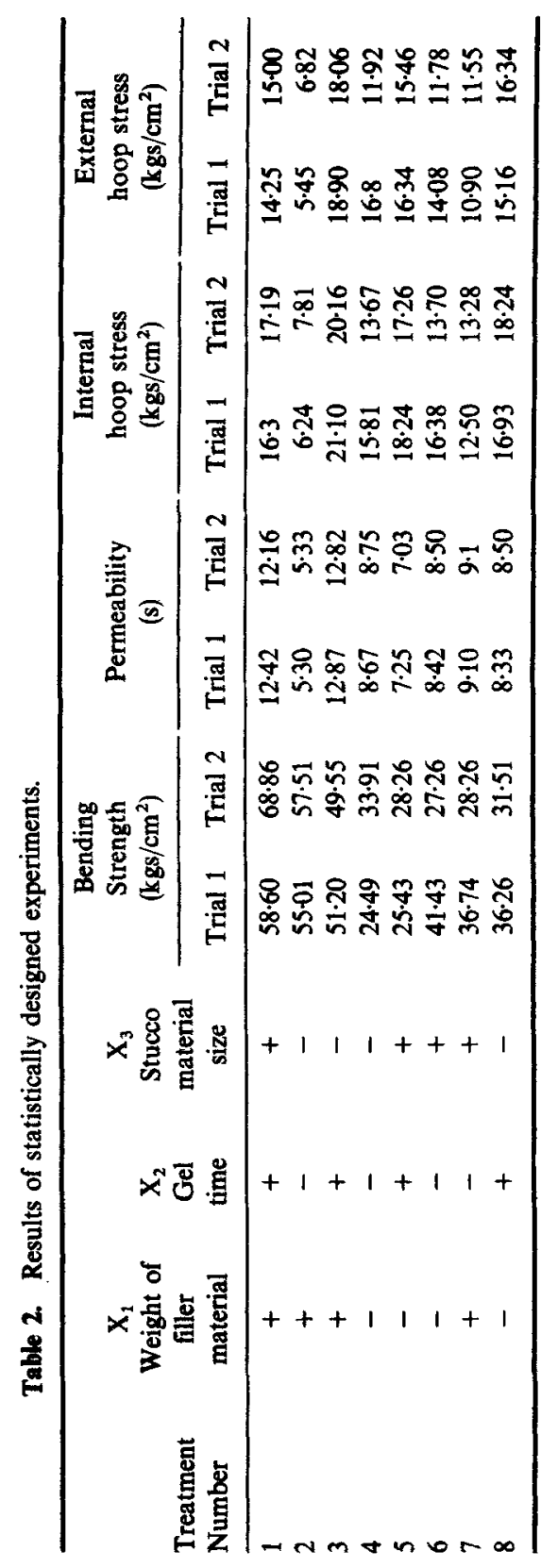




$$
\begin{aligned}
& Y_{B S}=40.98+9.74 x_{1}+2.86 x_{2}-1.58 x_{3}, \\
& Y_{P}=9.045+0.85 x_{1}+1 \cdot 14 x_{2}+0.21 x_{3}, \\
& Y_{I H S}=15.30-0.98 x_{1}+23.03 x_{2}+2 \cdot 45 x_{3}, \\
& Y_{E H S}=13.49-0.87 x_{1}+2.69 x_{2}+0.18 x_{3} .
\end{aligned}
$$

For bending strength, permeability, internal hoop stress and external hoop stress.

\subsection{Adequacy of linear model}

This may be confirmed by Fisher's ratio (Cochran and Cox 1959)

$$
F=S_{\mathrm{ad}}^{2} / S_{y},
$$

where, $S_{\mathrm{ad}}^{2}=$ variance of adequacy given by

$$
S_{\mathrm{ad}}^{2}=\sum_{1}^{N} n\left(\bar{Y}_{i}-Y_{i}\right)^{2} / f
$$

where $f$ is the degrees of freedom given by $N-(k+1)$ for a $2 k$ matrix. Here $N=8$ and $k=3$.

The experimental values of Fisher's ratios for bending strength, permeability, internal hoop stress and external hoop stress are found to be $8.05,1238.88,19.03$ and $17 \cdot 136$ respectively.

All these values are higher than 6.09 , which is the $F$ tabulated at $5 \%$ significant level for 4 degrees of freedom. Thus, a linear regression model is inadequate in all the cases considered.

\subsection{Regression model with interaction of variables}

Since a linear model is not suitable, it was decided to examine if a nonlinear model of the form,

$$
Y=a_{0}+a_{1} x_{1}+a_{2} x_{2}+a_{3} x_{3}+a_{4} x_{1} x_{2}+a_{5} x_{2} x_{3}+a_{6} x_{3} x_{1}+a_{7} x_{1} x_{2} x_{3},
$$

would be adequate instead. The regression equations thus obtained were,

$$
\begin{aligned}
& Y_{\mathrm{BS}}=40 \cdot 98+9 \cdot 74 x_{1}+2 \cdot 86 x_{2}-1 \cdot 5 x_{3}+3.48 x_{1} x_{2}+3.03 x_{2} x_{3}-1.07 x_{1} x_{3}+ \\
& 6.25 x_{1} x_{2} x_{3} \text {, } \\
& Y_{P}=9 \cdot 05+0 \cdot 85 x_{1}+1 \cdot 14 x_{2}+0 \cdot 21 x_{3}+15 x_{1} x_{2}-0 \cdot 68 x_{2} x_{3}+0 \cdot 6 x_{3} x_{1}- \\
& 0.41 x_{1} x_{2} x_{3} \text {, } \\
& Y_{\mathrm{IHS}}=15 \cdot 30-0 \cdot 98 x_{1}+2 \cdot 88 x_{2}+0 \cdot 31 x_{3}+1 \cdot 49 x_{1} x_{2}-1 \cdot 23 x_{2} x_{3}+0 \cdot 19 x_{3} x_{1} \\
& -1 \cdot 19 x_{1} x_{2} x_{3} \text {, } \\
& Y_{E H S}=13.49-0.87 x_{1}+2.69 x_{2}+0.18 x_{3}+1 \cdot 23 x_{1} x_{2}-1 \cdot 11 x_{2} x_{3}+0.13 x_{3} x_{1} \\
& -1 \cdot 13 x_{1} x_{2} x_{3} \text {. }
\end{aligned}
$$

By similar analysis the experimental $F$ ratio of the new model for bending strength, permeability, internal hoop stress and external hoop stress are $2.6 \times 10^{-4}$, $0.0189,2.094$ and $4.77 \times 10^{-4}$ respectively. These values are much lower than the tabulated Fisher's ratio (6.09). Thus this model is adequate for all the three parameters.

\subsection{Significance of the regression coefficients in the new model}

The confidence interval $\Delta b_{j}$ for a given parameter may be written as 


$$
\Delta b_{j}=t S(Y) / \sqrt{N}
$$

where $t$ is Student's $t$ at a $5 \%$ significance level and $S(Y)$ is the square root of the variance of reproducibility. The values of $\Delta b_{j}$ are calculated to be $4.5007,0.0855$, 0.792 and 0.89 respectively for bending strength, permeability, internal hoop stress and external hoop stress respectively. The significance of the coefficients in the new model is decided from the coefficient $\Delta b_{j}$. By retaining significant coefficients only, the final regression equations for the properties considered are,

(a) bending strength:

$$
\mathrm{BS}=4098+9 \cdot 74 x_{1}+6.25 x_{1} x_{2} x_{3}
$$

(b) permeability:

$$
P=9.05+0.85 x_{1}+1 \cdot 14 x_{2}+0.21 x_{3}+1 \cdot 15 x_{1} x_{2}+0.68 x_{2} x_{3}+0.6 x_{3} x_{1},
$$

(c) Internal hoop stress:

$$
\begin{aligned}
\text { IHS }= & 15.30-0.98 x_{1}+2.88 x_{2}+1.49 x_{2} x_{2}-1.23 x_{2} x_{3}-1.9 x_{1} x_{3} \\
& -0.41 x_{1} x_{2} x_{3},
\end{aligned}
$$

(d) external hoop stress:

$$
\mathrm{EHS}=13.49-0.87 x_{1}+2 \cdot 69 x_{2}+1 \cdot 23 x_{1} x_{2}-1 \cdot 11 x_{2} x_{3}-1 \cdot 13 x_{1} x_{2} x_{3} .
$$

In what follows the relation between each property and the variable will be examined and analysed.

4.6a Bending strength: The factors which largely affect the bending strength are the quantity of filler material and its interaction with the two other variables, viz. gelling time and stucco size. Strength increases with increase in the quantity of filler material used.

4.6b Permeability: All the parameters $x_{1}, x_{2}$ and $x_{3}$ individually and cumulatively influence permeability. Of the individual parameters, $x_{2}$ (gelling time), has maximum effect in a positive way.

4.6c Hoop stress: The highest degree of improvement in hoop strength is with gel time. A longer gel time is thus preferred for increase in hoop strength.

\section{Conclusions}

(1) A two-step hydrolysis is preferable to a single-step hydrolysis for making binders for investment moulds.

(2) The bench life of slurry made using the two-step hydrolysis is long.

(3) Higher bending strengths and permeabilities are obtained using larger quantities of filler material and with longer gel times.

(4) Hoop stress is increased by longer gel time and by using higher amounts of filler material.

(5) The grain size of stucco sand do not affect bending strength and hoop strength, but to some degree influences the permeability of the investment shell.

\section{References}

Babu K M 1988 Standardization of investment casting process using indigenous raw materials, $\mathrm{M}$ E thesis, M S Ramaiah Institute of Technology, Bangalore 
Busyman P and Van Embden H J M 1963 Foundry Trade J. 11415

Cochran W G and Cox G M 1959 Experimental designs (Asia Publishing House)

Doelman J 1966 Foundry Trade J. 724

Doskar J and Gabriel J 1967 Foundry 95(1) 146

Doskar J and Gabriel J 1967 Foundry $95(2) 92$

Kenny D J and Rutt P A 1959 Foundry 8782

Shah M 1975 Standardization of investment casting process, M E Project Report, Indian Institute of Science, Bangalore

Shepherd E J and Lewis 1989 Foundry Trade J. 107113

Tagger A A 1963 Russ. Cast. Prod. 430

Tkancheno K M and Rovnova V D 1963 Russ. Cast. Prod. 445 